\title{
When the Solvent Locks the Cage: Theoretical Insight into the Transmetalation of MOF-5 Lattices and Its Kinetic Limitations
}

\author{
Luca Bellarosa, ${ }^{* \dagger}$ Carl K. Brozek, ${ }^{\ddagger}$ Max García-Melchor, ${ }^{\dagger, \S}$ Mircea Dincă, ${ }^{\ddagger}$ and Núria López ${ }^{\dagger}$ \\ ${ }^{\dagger}$ Institute of Chemical Research of Catalonia, ICIQ, Av. Països Catalans 16, 43007 Tarragona, Spain \\ ${ }^{\ddagger}$ Department of Chemistry, Massachusetts Institute of Technology, 77 Massachusetts Avenue, Cambridge, Massachusetts 02139, \\ United States \\ ${ }^{\S}$ SUNCAT Center for Interface Science and Catalysis, SLAC National Accelerator Laboratory, Menlo Park, California 94025 , United \\ States
}

Supporting Information

\begin{abstract}
Transmetalation is an innovative postsynthetic strategy for tailoring the properties of metal-organic frameworks (MOFs), allowing stable unprecedented metal coordination environments. Although the experimental synthetic protocol is wellestablished, the underlying mechanism for transmetalation is still unknown. In this work, we propose two different solvent-mediated reaction paths for the Ni transmetalation in $\mathrm{Zn}$ MOF-5 lattices through density functional theory simulations. In both mechanisms, the bond strength between the exchanged metal and the solvent is the key descriptor that controls the degree of transmetalation. We also show that the role of the solvent in this process is twofold: it initially promotes $\mathrm{Zn}$ exchange, but if the metal-solvent bond is too strong, it blocks the second transmetalation cycle by restricting the lattice flexibility. The competition between these two effects leads the degree of incorporation of metal into MOF-5 to display a volcano-type dependence with respect to the metal-solvent bond strength for different transition metal ions.
\end{abstract}

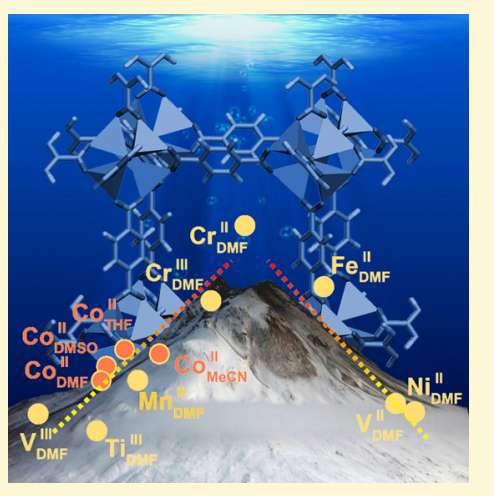

\section{INTRODUCTION}

The easiness with which metal-organic frameworks (MOFs) ${ }^{1}$ can swap their constituents with the surrounding medium is crucial for creating novel structures with tailored properties. This process, called postsynthetic modification, ${ }^{2}$ can yield cations in awkward coordinations that cannot be reached by synthesis from scratch. ${ }^{2-4}$ The tremendous potential of these modified compounds with open sites in the field of catalysis, ${ }^{5,6}$ separation, ${ }^{7}$ and $\mathrm{CO}_{2}$ sequestration ${ }^{8,9}$ opens an immense field of research. ${ }^{10}$ Generally, postsynthetic treatments occur without affecting the topology of the compound in a single-crystal-tosingle-crystal transformation, ${ }^{11,12}$ implying that the formation and cleavage of metal-ligand bonds occur while the overall MOF architecture is maintained. ${ }^{13}$ In particular, with postsynthetic ion metathesis (PSIM) ${ }^{14-19}$ the original cation in the MOF lattice can be replaced by divalent or even trivalent cations. The metal substitution often saturates, ${ }^{20-23}$ not reaching full ion exchange. This is the case for Ni in MOF-5, whose maximal Ni: $\mathrm{Zn}$ ratio is $1: 3$ at room temperature. ${ }^{24}$

Four factors have been proposed to control ion exchange: (i) the ionic radii and the coordination modes of the exchanged metals, ${ }^{25}$ (ii) the pore diameter and framework flexibility of the network, ${ }^{25}$ (iii) the difference in electronegativity between the incoming and leaving metal, ${ }^{2}$ and (iv) the solvent. ${ }^{26}$ Some solvent parameters like polarizability, donor indexes, and dielectric constants correlate poorly with the transmetalation extent. However, solvent Lewis basicity and the ligand field parameter have been shown to correlate with the rate of
PSIM. ${ }^{26}$ Nevertheless, the dependence on the ligand field was found to be opposite for $\mathrm{Ni}$ inserting into MOF-5 and Co into MFU-4l. Besides PSIM in MOF, solvent also plays a critical role in linker exchange, ${ }^{27-31}$ MOF interpenetration, ${ }^{32}$ and reconstruction, ${ }^{33}$ and ion metathesis in zeolites. ${ }^{34}$

Simulations hold the key to unraveling the precise role of each of the contributions described above, in particular the solvent role. ${ }^{35-37}$ However, because of the large size of the MOF lattices, a plethora of competing intermediate states, and the challenges induced by the large flexibility of the lattice, no transmetalation mechanism has yet been proposed.

Here we present a first-principles theoretical study of the ion exchange mechanism in MOF-5 structures and its dependence on the solvent nature. Two routes can account for the $\mathrm{Ni}$ transmetalation in MOF-5. In both paths, the incorporation of the first $\mathrm{Ni}$ is actively promoted by the medium, but solvent leftovers prevent any other metal substitution. The strength of the metal-solvent parameter dictates the kinetics of the incorporation process, thus emerging as the sole descriptor of the transmetalation process. The implications of this effect overstep the boundaries of reactivity and account for the increased robustness to moisture degradation upon transmetalation with $\mathrm{Ni}$. 


\section{THEORETICAL MODEL}

MOF-5 can be described as a cubic crystal structure, where the corners consist of zinc oxide tetrahedral units, $\left(\mathrm{Zn}_{4} \mathrm{O}\right)^{6+}$, connected to each other by 1,4-benzenedicarboxylates $\left(\mathrm{BDC}^{2-}\right)$ forming an alternating chain in which each phenyl group is twisted by $90^{\circ}$ (see Figure 1a). This lattice has a

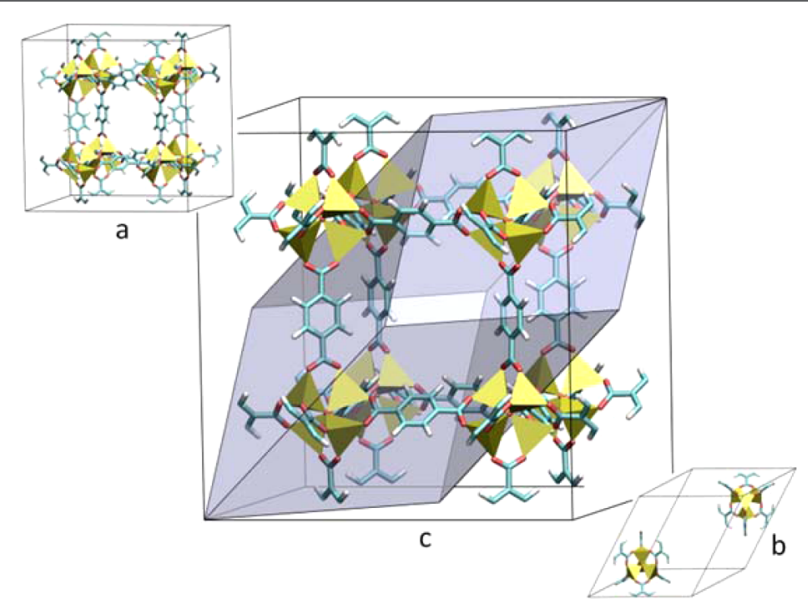

Figure 1. (a) Crystallographic cubic lattice with eight $\mathrm{Zn}_{4} \mathrm{O}(\mathrm{BDC})_{3}$ subunits. (b) Primitive rhombohedral unit cell of MOF-5 used in simulations with two $\mathrm{Zn}_{4} \mathrm{O}(\mathrm{BDC})_{3}$ subunits. (c) Rhombohedral cell (transparent blue) enclosed within the more commonly employed crystallographic cubic lattice. Color code: cyan, carbon; white, hydrogen; red, oxygen. $\mathrm{Zn}$ atoms sit at the center of yellow tetrahedra.

$\left[\mathrm{Zn}_{4} \mathrm{O}(\mathrm{BDC})_{3}\right]_{8}$ stoichiometry. An alternative representation of the MOF-5 lattice is the rhombohedral system shown in panels $b$ and $c$ of Figure 1, whose unit cell contains two rotated $\mathrm{Zn}_{4} \mathrm{O}(\mathrm{BDC})_{3}$ subunits. This representation reduces the size of the unit cell and the computational burden; therefore, it was employed for the calculations in this work. Convergence tests to check the quality of this model are presented in section 1 of the Supporting Information.

\section{RESULTS AND DISCUSSION}

Thermodynamics. We began our study by systematically substituting $\mathrm{Zn}$ atoms in the rhombohedral cell with $\mathrm{Ni}$ atoms, up to full replacement in one of the cores $(x=4)$, according to eq 1:

$$
\begin{aligned}
& \mathrm{Zn}_{8}\left(\mu_{4}-\mathrm{O}\right)_{2}(\mu-\mathrm{BDC})_{6}+x \mathrm{Ni}(\mathrm{DMF})_{6}{ }^{2+} \\
& \quad \rightarrow \mathrm{Zn}_{8-x} \mathrm{Ni}_{x}\left(\mu_{4}-\mathrm{O}\right)_{2}(\mu-\mathrm{BDC})_{6}+x \mathrm{Zn}(\mathrm{DMF})_{6}{ }^{2+}
\end{aligned}
$$

where DMF is $N, N$-dimethylformamide. The results of these calculations are shown in Figure 2, as green bars. For the dry MOF-5 without any solvent attached, each Zn-by-Ni substitution destabilizes the lattice by a constant contribution of $\sim 0.47 \mathrm{eV} / \mathrm{Ni}$ (Figure 2, green bars, bottom panel). Considering the synthetic procedure and the temperature range at which the reaction occurs, ${ }^{24}$ an upper limit for the energy barrier of the process can be estimated to be $1.3 \mathrm{eV}$ using the Arrhenius equation (dashed black line in Figure 2). Thus, thermodynamic considerations point out that two nickel atoms, or three at most, can be exchanged in the same $\mathrm{Zn}_{4} \mathrm{O}$ core under the current setup (2:2 or 3:1 Ni:Zn), different from the $\mathrm{Ni}: \mathrm{Zn}$ ratio of $1: 3$ seen in the experiments.

Nevertheless, the presence of solvent adsorbed on the MOF is unavoidable (see sections 2 and 3 of the Supporting

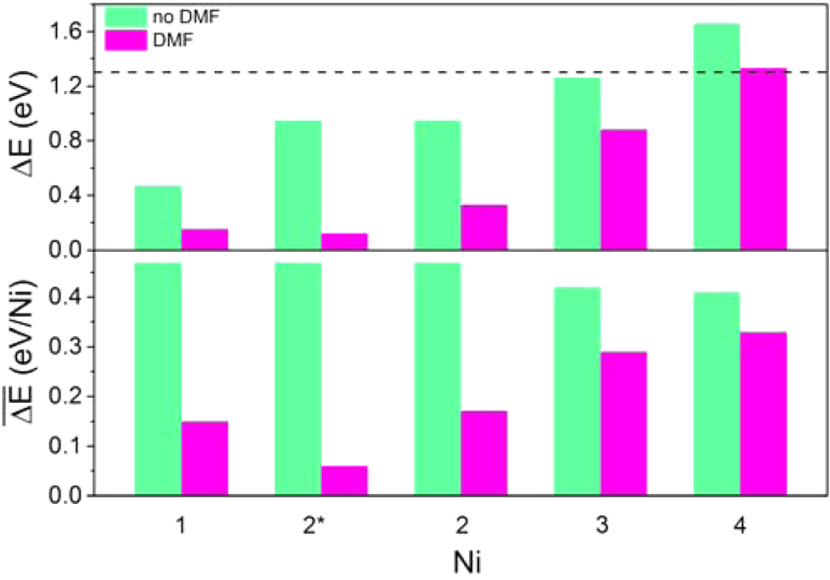

Figure 2. Reaction energy (top, $\Delta E$ in electronvolts) for the replacement of one or more $\mathrm{Zn}$ atoms with $\mathrm{Ni} . \mathrm{Ni}=1,2$, 3, or 4: substitution on the same subunit of the simulation cell; $\left[\mathrm{Zn}_{4} \mathrm{O}\right.$ $\left.(\mathrm{BDC})_{3}\right]\left[\mathrm{Ni}_{x} \mathrm{Zn}_{4-x} \mathrm{O}(\mathrm{BDC})_{3}\right]$ stoichiometry $(x=1-4) . \mathrm{Ni}=2^{*}$ : substitution on different subunits; $\left[\mathrm{NiZn}_{3} \mathrm{O}(\mathrm{BDC})_{3}\right]_{2}$ stoichiometry. Contribution per $\mathrm{Ni}$ atom (bottom). The energy is for the reaction in eq 1 (green bars) or eq 2 with two DMF molecules on MOF-5 (magenta bars). The dashed line is the maximal $\Delta E$ that can be reached with the experimental setup.

Information), and thus, it is likely that the lattice cores are coordinated to it before the substitution takes place. Thus, the reaction for the ion metathesis with different content $(y)$ of DMF (S) coordinated to MOF-5 can be written as

$$
\begin{aligned}
& \mathrm{Zn}_{8}\left(\mu_{4}-\mathrm{O}\right)_{2}(\mu-\mathrm{BDC})_{6} \cdot \mathrm{S}_{y}+x \mathrm{NiS}_{6}{ }^{2+} \\
& \quad \rightarrow \mathrm{Zn}_{8-x} \mathrm{Ni}_{x}\left(\mu_{4}-\mathrm{O}\right)_{2}(\mu-\mathrm{BDC})_{6} \cdot \mathrm{S}_{y}+x \mathrm{ZnS}_{6}{ }^{2+}
\end{aligned}
$$

For this reaction, we explored different DMF contents $(y \leq 8$ DMFs/core) and several configurations for the solvated cell. A plethora of structures lying within a narrow energy window was found. All these geometries can be interpreted as the combination of three stable basic patterns; further details can be found in sections 2 and 3 of the Supporting Information. The presence of solvent (magenta bars in Figure 2) makes it thermodynamically feasible to place up to three $\mathrm{Ni}$ atoms on the metal core $(3: 1 \mathrm{Ni}: \mathrm{Zn})$. Therefore, thermodynamics does not limit the extent of $\mathrm{Ni}$ substitution, indicating that the exchange may exhibit a kinetic control.

Our results thus agree with the experimental suggestion that kinetic limitations rather than thermodynamic ones are responsible for the limits in the transmetalation process. ${ }^{24}$ However, the process is found to be slightly endothermic, at odds with earlier suggestions. ${ }^{24}$ The energies of binding of the solvent to the substituted Ni-MOF-5 structure are $0.88 \mathrm{eV}$ (first solvation of $\mathrm{Ni}$ atom) and $1.41 \mathrm{eV}$ (second solvation), values that agree with the requirement of high temperatures required to eliminate solvent and change the coordination sphere from six to four $\left(100\right.$ and $\left.200{ }^{\circ} \mathrm{C}\right) .{ }^{24}$

Transmetalation Mechanisms. The kinetic limitations that apply to the Ni transmetalation in MOF-5 compounds can be described within the present DFT methodology. In a recent review, ${ }^{2}$ two main mechanisms have been put forward at the base of the transmetalation phenomenon: associative and dissociative. We systematically examined both in detail. Each intermediate has been labeled according to the coordination of the incoming $\mathrm{Ni}$ and outgoing $\mathrm{Zn}$ atoms. The subscripts in 
each label stand for the number of the oxygens from MOF left on either $\mathrm{Zn}$ or $\mathrm{Ni}$ (labeled $\mathrm{O}_{1}$ if they belong to $\mathrm{BDC}^{2-}$ or $\mathrm{O}_{\mathrm{c}}$ if it is the central oxide). On the other hand, the superscripts specify how many oxygens from the DMF solvent, $\mathrm{O}_{d}$, are coordinated to the metal center.

Associative Mechanism. Ion metathesis mechanisms reported for homogeneous catalysts ${ }^{38}$ usually involve intermediates for which the entering and leaving metals are coordinated to common ligands and are free to exchange their substituents, i.e., in an associative way. Thus, we propose a similar mechanism in which the entering $\mathrm{Ni}(\mathrm{DMF})_{6}{ }^{2+}$ complex anchors to the $\mathrm{Zn}_{4} \mathrm{O}$ core and, step by step, swaps DMF molecules for the $\mathrm{BDC}^{2-}$ linker.

In the starting geometry represented in Figure $3 \mathrm{~b}$ (and easily reached by the desolvation of Figure $3 a$ ), the core can rapidly

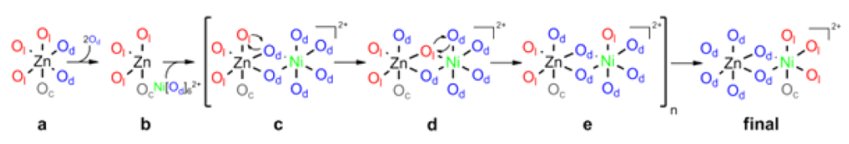

Figure 3. Schematic representation for the initial steps of the replacement of one $\mathrm{O}_{d}$ on $\mathrm{Ni}$ by $\mathrm{O}_{1}$ in the associative mechanism of the transmetalation of MOF-5. Reiteration of steps $\mathrm{c}-\mathrm{e}$ yields the final lattice Ni-MOF-5. Only the substituted $\mathrm{Zn}$, the incoming $\mathrm{Ni}$, and their surrounding oxygens are shown for the sake of clarity. Oxygen atom label code: $\mathrm{O}_{\mathrm{l}}$, from the linker; $\mathrm{O}_{\mathrm{d}}$, from DMF; $\mathrm{O}_{\mathcal{c}}$ from the $\mathrm{Zn}_{4} \mathrm{O}$ core.

accommodate an approaching $\mathrm{Ni}(\mathrm{DMF})_{6}{ }^{2+}$, forming a complex with two bridging DMF molecules. With the $\mathrm{Ni}^{2+}$ anchored to the lattice and close to the outgoing $\mathrm{Zn}^{2+}$ ion, the two cations can start exchanging substituents (Figure 3c). Passing through an intermediate where $\mathrm{O}_{1}$ bridges both metals (Figure 3d), it is ultimately transferred to $\mathrm{Ni}$ (Figure $3 \mathrm{e}$ ). Elementary steps c-e continue until full replacement of the ligand oxygens around $\mathrm{Zn}$ is reached and the newly formed $\mathrm{Zn}(\mathrm{DMF})_{4}{ }^{2+}$ unit detaches from the lattice. For the reaction to reach completeness, bridging ligands between the metal centers are needed to keep the Ni complex in place. The possible intermediates spawned by this simple mechanism are presented in section 4 of the Supporting Information. The energy profile in Figure 4 corresponds to the lowest-energy route. The final configuration $\mathrm{Zn}_{0}^{6} \mathrm{Ni}_{4}^{2}$ in the first transmetalation cycle is the starting point for the second cycle, colored cyan in Figure 4. In this case, the Ni at the core cannot easily lose its bound DMF ligands; the energy of binding of DMF to the $\mathrm{Ni}$ centers in the $\mathrm{Ni}$ substituted MOF-5 is $0.73 \mathrm{eV}$. Therefore, the second cycle starts with $\mathrm{Zn}_{4}^{2} \mathrm{Ni}_{0}^{6}$, but with $\mathrm{Ni}$ in an octahedral environment. This $\mathrm{Ni}(\mathrm{DMF})_{2}$ unit freezes the metal core, locking the lattice into a stiff geometry, which is less prone to geometric rearrangements.

One key feature of the proposed mechanism is the ability of the solvent to bridge $\mathrm{Zn}$ and $\mathrm{Ni}$ atoms to exchange their substituents. DMF molecules connect the entering and leaving ions and stabilize all the intermediates. Thus, solvent molecules with just one lone pair available for coordination will not be able to transmetalate via the associative route. Another important feature of this mechanism is its locality: the reaction happening on one core creates local distortions that do not

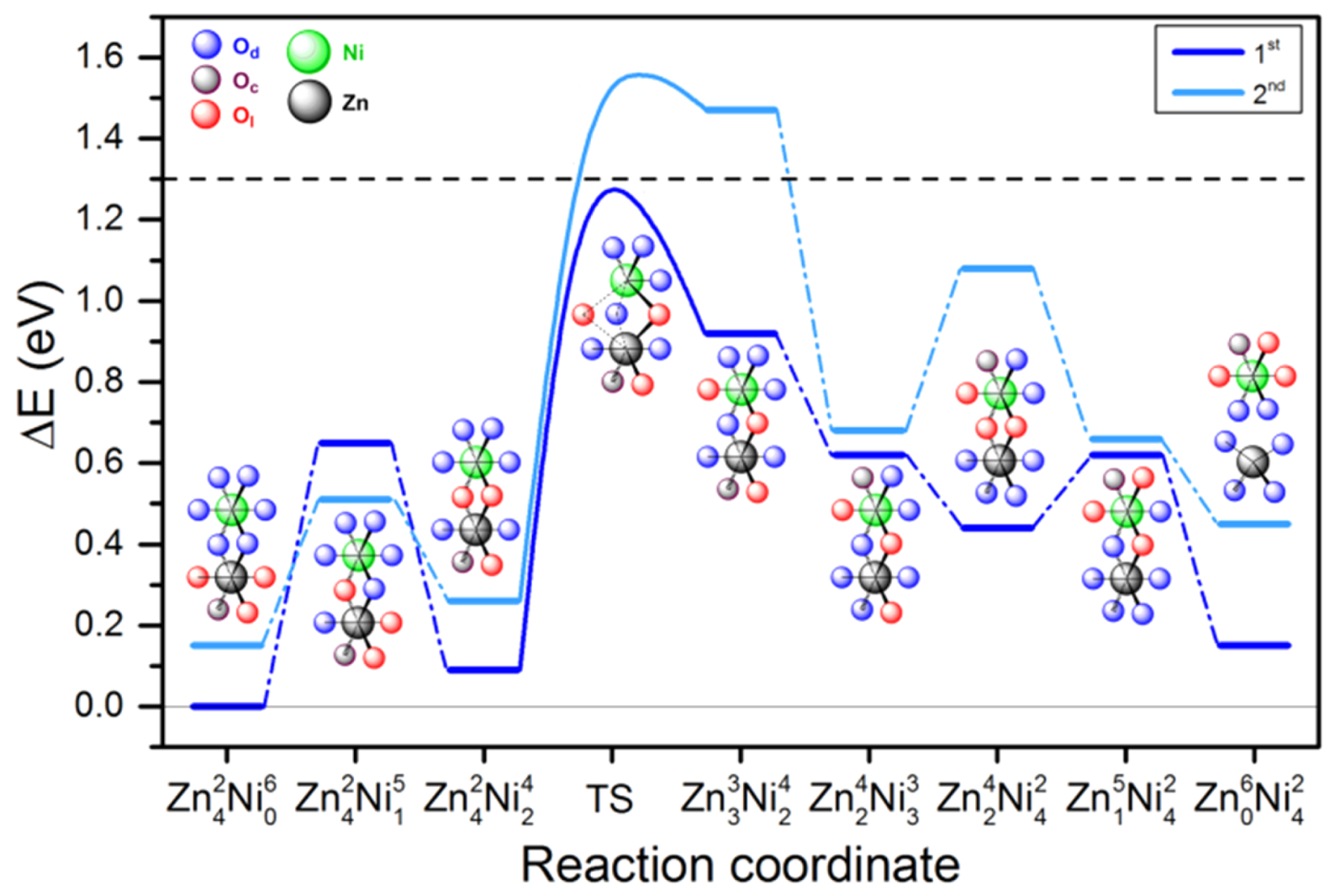

Figure 4. Energy profile for the associative mechanism. Blue lines indicate the most stable intermediates for the first transmetalation cycle and cyan lines those for the second cycle. The nomenclature at each step enumerates the coordination left on each metal atom: from the lattice $\left(\mathrm{O}_{1} / \mathrm{O}_{c}\right)$ as subscripts and solvent $\left(\mathrm{O}_{\mathrm{d}}\right)$ as superscripts. The dashed line is the maximal $\Delta E$ compatible under reaction conditions. The final product of the first transmetalation cycle, $\mathrm{Zn}_{0}^{6} \mathrm{Ni}_{4}^{2}$, is the initial state for the second transmetalation cycle. 
propagate through the lattice. That is, the associative mechanism does not create any stress on the MOF topology, thus leaving the nearby cores unperturbed.

Dissociative Mechanism. The dissociative mechanism presented in Figure 5 takes place when the bond between the

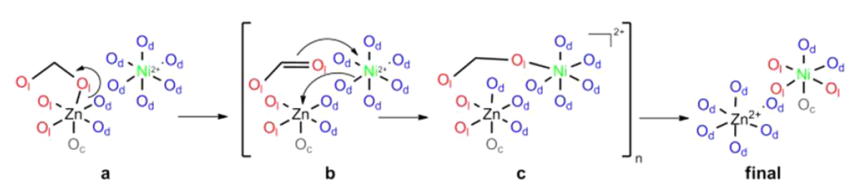

Figure 5. Schematic representation for the initial steps of the replacement of one $\mathrm{O}_{d}$ on $\mathrm{Ni}$ by $\mathrm{O}_{1}$ in the dissociative mechanism of the transmetalation of MOF-5. Reiteration of steps $b$ and $c$ yields the final lattice Ni-MOF-5. Only the substituted $\mathrm{Zn}$, the incoming $\mathrm{Ni}$, and their surrounding oxygens are shown. Same labeling as for Figure 3.

organic linker and the metal in the MOF is not too strong and can break, especially if it is displaced by the solvent. In absence of solvent, we computed that breaking a $\mathrm{Zn}-\mathrm{O}_{1}$ bond yields a structure with a $1.06 \mathrm{eV}$ higher energy. This difference can be reduced depending on the degree of interaction of the medium with the $\mathrm{Zn}$ at the core. ${ }^{39}$ In the case of DMF, it is just $0.45 \mathrm{eV}$, which indicates that this route can be feasible. We therefore investigated in depth this route and its competition with the associative one.

The initial step involves the active participation of the DMF that, solvating the $\mathrm{Zn}$ atom, induces breaking of a $\mathrm{Zn}-\mathrm{O}_{1}$ bond (Figure 5a), thus resulting in a swinging carboxylic group
(Figure $5 b$ ). This group is then free to coordinate to a nearby $\mathrm{Ni}(\mathrm{DMF})_{6}{ }^{2+}$ (Figure $5 \mathrm{c}$ ). Elementary steps $\mathrm{b}$ and $\mathrm{c}$ repeat until complete substitution is achieved. The saturating DMF molecules that form the coordination sphere of the fleeing $\mathrm{Zn}$ can come from the solvent reservoir or from the incoming cluster. For the sake of simplicity, we investigated only the latter option. The lowest-energy profile for this mechanism is presented in Figure 6.

The first step is the approach of the $\mathrm{Ni}(\mathrm{DMF})_{6}{ }^{2+}$ cluster to one face of the core. Then, the replacement of one carboxylate unit in a $\mathrm{Zn}$ center by $\mathrm{DMF}$ takes place, yielding the intermediate $\mathrm{Zn}_{3}^{3} \mathrm{Ni}_{0}^{6}$. The $\mathrm{COO}^{-}$moiety successively coordinates to $\mathrm{Ni}(\mathrm{DMF})_{6}{ }^{2+}$, leading to the next intermediate $\mathrm{Zn}_{3}^{3} \mathrm{Ni}_{1}^{5}$. $\mathrm{Zn}-\mathrm{OCO}$ decoordination and $\mathrm{COO}-\mathrm{Ni}$ coordination are then repeated until the intermediate $\mathrm{Zn}_{2}^{4} \mathrm{Ni}_{2}^{4}$ is reached. $\mathrm{Up}$ to this point, two $\mathrm{O}_{1}$ atoms of one $\mathrm{Zn}$ center have been replaced by two $\mathrm{O}_{\mathrm{d}}$ atoms, and $\mathrm{Ni}$ is coordinated to two $\mathrm{O}_{1}$ atoms coming from two different $\mathrm{Zn}$ atoms, as shown in the inset of Figure 6 .

The proximity of $\mathrm{Ni}$ to $\mathrm{O}_{\mathrm{c}}$ hints at the following intermediate $\mathrm{Zn}_{3}^{1} \mathrm{Ni}_{3}^{3}$, where the $\mathrm{Ni}-\mathrm{O}_{\mathrm{c}}$ bond is formed and the nearby $\mathrm{Zn}$ center, $\mathrm{Zn}_{\alpha}$, withdraws another DMF molecule. The optimization of this structure yields a detachment of the $\mathrm{Zn}$ atom opposite to $\mathrm{Ni}$ from $\mathrm{O}_{\mathcal{c}} \mathrm{Zn}_{\beta}$ (gray in Figure 5). ${ }^{40}$ Thus, the dissociative path follows a $\mathrm{S}_{\mathrm{N}} 2$-type reaction mechanism whose barrier is $1.22 \mathrm{eV} . \mathrm{Zn}_{\beta}$ (colored light gray in the labels of Figure 6) is still connected to three $\mathrm{O}_{1}$ atoms in a $\mathrm{Zn}_{3}^{1} \mathrm{Ni}_{3}^{3}$ geometry, but this open structure favors the replacement of two $\mathrm{O}_{1}$ atoms with $\mathrm{O}_{\mathrm{d}}$, passing through the intermediate $\mathrm{Zn}_{2}^{2} \mathrm{Ni}_{3}^{3}$ and

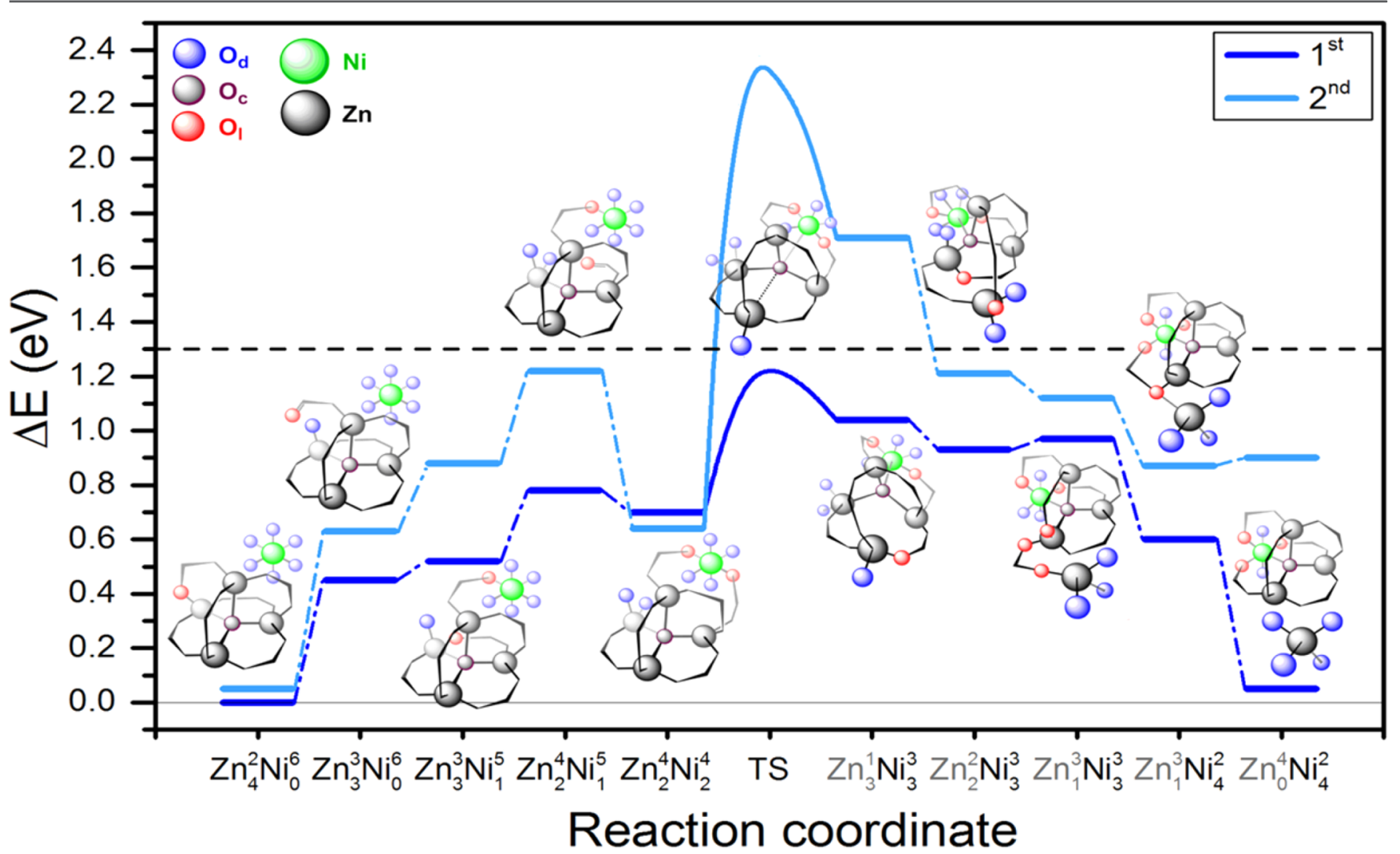

Figure 6. Energy profile for the dissociative mechanism. The $\mathrm{Zn}$ where the attack starts (black) and the leaving group (gray) are different. Blue lines indicate the most stable intermediates for the first cycle and cyan lines those for the second cycle. The dashed line is the maximal $\Delta E$ compatible at reaction conditions. The final product of the first transmetalation, $\mathrm{Zn}_{0}^{4} \mathrm{Ni}_{4}^{2}$, is the initial state for the second transmetalation. Please note that the energies of products $\mathrm{Zn}_{0}^{4} \mathrm{Ni}_{4}^{2}$ are different from the values in Figure 2 because they refer to different structures. 
quickly converging to $\mathrm{Zn}_{1}^{3} \mathrm{Ni}_{3}^{3}$. All these structures are characterized by a stressed metal core $\mathrm{Zn}_{3} \mathrm{NiO}$, due to the inversion of the configuration of the $\mathrm{S}_{\mathrm{N}} 2$ mechanism.

Nevertheless, in each step, tetrahedral unit $\mathrm{Zn}_{3} \mathrm{NiO}$ rotates slightly, as sketched in the inset of Figure 5, thus restoring the initial orientation at the third intermediate. The shift of the final carboxylate creates stable intermediate $\mathrm{Zn}_{1}^{3} \mathrm{Ni}_{4}^{2}$ with the $\mathrm{Zn}_{3} \mathrm{NiO}$ core already formed, and the $\mathrm{Zn}\left(\mathrm{O}_{\mathrm{d}}\right)_{3}$ cluster still sharing one $\mathrm{O}_{1}$ with one $\mathrm{Zn}$. Adding DMF removes this solvated cluster completing the first transmetalation cycle.

The second transmetalation on the newly formed $\mathrm{Zn}_{3} \mathrm{NiO}$ core follows in principle the same steps as the first one, but the inequality of the metal centers at the core spawns more intermediates during the transmetalation. In Figure 6, the minimal energy path is reported, whereas all the other structures are described in section 6 of the Supporting Information. Again, the newly added $\mathrm{Ni}(\mathrm{DMF})_{2}$ unit stiffens the core, thus increasing the energies of all the reaction intermediates. The lost flexibility of the core takes its toll on the TS, where the transfer of the $\mathrm{O}_{\mathrm{c}}$ from $\mathrm{Zn}$ to the newly entered $\mathrm{Ni}$ is $>2.3 \mathrm{eV}$, and thus $1.1 \mathrm{eV}$ higher than for the first transmetalation. Moreover, the resulting intermediate $\mathrm{Zn}_{3}^{1} \mathrm{Ni}_{3}^{3}$ is too unstable to be accessible, thus making the second transmetalation via the dissociative mechanism unlikely. Details for the crucial transition state for each ion replacement are reported in section 7 of the Supporting Information.

Overall, the dissociative route follows an $\mathrm{S}_{\mathrm{N}} 2$-type mechanism, a process not unprecedented in a solid state. ${ }^{41}$ In this particular case, it occurs with inversion of configuration at the metal core, generating a torque on the nearby organic linkers that breaks the planarity of the BDC linkers by twisting the carboxylates. This stress propagates to the other cores and can ease the transmetalation of the nearby centers. Hence, unlike the associative mechanism, transmetalating one core can induce the transformation of others, in a domino-like effect.

Another key feature of this mechanism is its strong dependence on the substrate. In the case of MOF-5, DMF eases the cleavage of the $\mathrm{Zn}-\mathrm{O}_{1}$ bond and stabilizes the resulting intermediate. For MOF materials with firm metalorganic linker bonds, or very rigid bonds, or that weakly interact with solvent, the dissociative path could be strongly hindered, if at all possible. It heavily relies on the ability of the metal ions in the core to cut loose from the nearby organic linkers, especially in the presence of solvent. On the other hand, intermediates are not stabilized by any bridges with the solvent, implying that any solvent that can adsorb on MOF-5 can convey dissociative transmetalation.

Comparison to Experimental Results. Experimental data provide scarce but useful insight for mechanistic interpretation. First, Ni transmetalation of MOF-5 occurs on the time scale of a year at room temperature. ${ }^{24}$ According to the Arrhenius equation, this implies a reachable energy of $\sim 1.3 \mathrm{eV}$ at maximum (see section 8 of the Supporting Information). The inspected mechanisms present a first cycle lower than this value; thus, both are compatible with this requirement. In addition, experiments point to the fact that the limitations for transmetalation are of kinetic origin; this agrees with the difficulties imposed by a solvent-crowded environment around the $\mathrm{Ni}$ atom that limits further incorporation of the second ion. Moreover, the energy of binding of the solvent to $\mathrm{Ni}$ is in line with the temperature requirements in the TGA experiments for removal of the remaining solvent to Ni-MOF-5. ${ }^{24}$ Finally, the estimate for the reaction order of $\mathrm{Ni}$ in the incorporation measured by initial incorporation rates is roughly $\approx 0.7$, as reported in section 8 of the Supporting Information. This value is obtained from the data in the Supporting Information of ref 24 . In the case presented here, a reaction order of $<1$ comes from the role of the $\mathrm{Ni}$ incorporated into the lattice and still solvated that blocks further ion replacement.

Generalization to Other Ions. According to the energy barriers presented previously, the incorporation of $\mathrm{Ni}$ into the MOF-5 cores can evolve through any of the two proposed mechanisms, although, depending on the solvent and the substrate, one or the other might be favored. Despite their differences, solvent plays a key role in both of them. In the case of the associative route, its presence is essential during the attachment of the incoming ion to the lattice, its coordination to the carboxylate ligands, and the dissociation of the outgoing solvated $\mathrm{Zn}$ ion. With regard to the dissociative mechanism, solvent frees $\mathrm{Zn}$ centers from the carboxylic units, stabilizes $T_{d}$ metals during the intermediates, and helps to remove the $\mathrm{Zn}$ leftover attached to the core. In both mechanisms, the solvent leftover on the replacing $\mathrm{Ni}$ stiffens the secondary building unit, making it less prone to geometric rearrangements and thus shielding it against the attack of incoming ions. Therefore, of the four main reasons governing transmetallation and described in the introduction, we have found that the solvent (iv) plays a major role as it is able to induce the reaction and also to selflimit it by increasing the rigidity of the lattice (v).

In both mechanisms, the crucial step is characterized by a $\mathrm{Ni}_{4}^{2}$ configuration ( $\mathrm{Ni}$ atom surrounded by four $\mathrm{O}_{d}$ molecules and two $\mathrm{O}_{1}$ molecules), ready to share (associative) or lose (dissociative) one DMF to coordinate the organic linker. This common feature induced us to think that a common descriptor, the strength of the metal-solvent bond, could be the key parameter that controls the kinetics of the reaction. We thus performed a kinetic analysis (reported in section 9 of the Supporting Information) that shows that the rate constant of both mechanisms displays a very similar dependence on the metal-solvent bond strength.

Therefore, to investigate the crucial role of the medium in the PSIM process, we have considered several experiments reporting the degree of incorporation in the MOF-5 lattice for different metals, including di- and trivalent ions. ${ }^{14} \mathrm{We}$ employed a training set consisting of eight points corresponding to several ions in DMF $\left(\mathrm{M}=\mathrm{Cr}{ }^{\mathrm{II} / \mathrm{III}}, \mathrm{Fe}^{\mathrm{II}}, \mathrm{Mn}^{\mathrm{II}}, \mathrm{Ni}^{\mathrm{II}}, \mathrm{Ti}^{\mathrm{III}}\right.$, or $\left.\mathrm{V}^{\mathrm{II} / \mathrm{III}}\right)$. For these ions, we probed the incorporation of the metal in MOF-5 after 1 week at room temperature following the standard experimental procedure. These experimental values ( $y$ in Figure 7) provide an average rate for ion transmetalation. The descriptor controlling the interaction $(x$ values in Figure 7) is computed as the energy required to remove a solvent molecule from the solvated metal before its incorporation into the lattice. Further details about how these energies have been obtained can be found in section 10 of the Supporting Information. The training set results are shown in Figure 7 marked by filled circles.

Transmetalation of MOF-5 follows a typical volcano behavior (lines are a guide to the eye), a common phenomenon in catalysis. ${ }^{42,43}$ The origin of this trend stems from the dependence of the reaction on one key common descriptor, i.e., the metal-solvent bond strength. We validate this assumption confronting it with an added test set of four more points (empty circles in Figure 7), with $\mathrm{M}=\mathrm{Co}^{\mathrm{II}}$ and $\mathrm{L}=$ acetonitrile or MeCN, DMF, dimethyl sulfoxide or DMSO, and THF. The new points fit nicely in the existing plot. Although the kinetics 


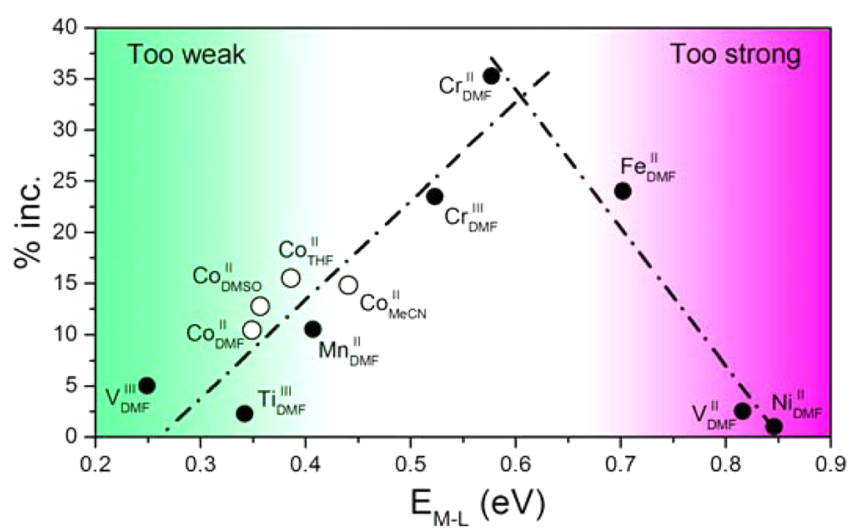

Figure 7. Degree of incorporation of different metals into the MOF-5 lattice after 1 week at room temperature, ${ }^{14}$ as a function of the metalsolvent bond energy, $E_{\mathrm{M}-\mathrm{L}}$ (positive values denote exothermic energies). The lines are a guide to the eye and stand for a bond that is too weak (left) or too strong (right). Filled circles belong to the training set, while empty circles are a test set. Subscripts refer to the solvent medium and superscripts to the formal oxidation state of the metal.

for the two mechanisms are similar, different interpretations depending on the transmetalation route are at the base of this trend.

The associative mechanism is possible in all the cases reported in Figure 7 except for $\mathrm{Co}^{\mathrm{II}}$ in $\mathrm{MeCN}$, because the solvent cannot form bridges between the replacing metal and the MOF core. Were the $\mathrm{M}-\mathrm{O}_{\mathrm{d}}$ bond too weak, the solvated $\mathrm{M}$ ion would superficially interact with the lattice, thus inhibiting the formation of the first intermediate, $\mathrm{Zn}_{4}^{2} \mathrm{M}_{1}^{5}$. As a rule of thumb, if the average metal-solvent interaction energy is smaller than the $\mathrm{Zn}$-solvent interaction energy $(0.53 \mathrm{eV}$ for DMF), the lattice would withdraw the solvent from the solvated ion, and this would detach quickly without any ligand exchange. On the other hand, if the $\mathrm{M}-\mathrm{O}_{\mathrm{d}}$ bond is too strong, the steps that require $\mathrm{M}-\mathrm{O}_{\mathrm{d}}$ bond cleavage or sharing would be too energy demanding.

On the other hand, the dissociative mechanism, possible in all the examined cases, would initially benefit from a weak $\mathrm{M}-\mathrm{L}$ bond, considering that the first steps involve desolvation of the metal cluster. Nevertheless, after the TS geometries would be too high in energy for the reaction to proceed, because solvent is needed to stabilize the replacing metal and lower the stress on the metal core. As for the associative mechanism, the energy of the intermediates that involve $\mathrm{M}-\mathrm{L}$ bond cleavage would increase if its energy is too high.

\section{CONCLUSIONS}

We have proposed two possible transmetalation mechanisms for the MOF-5 lattices that explain the kinetic control that dominates ion exchange in these materials. In the associative route, the incoming $\mathrm{Ni}$ cluster and the MOF lattice create complex bridged structures stabilized by the oxygen lone pairs of the solvent. The metal exchange through this mechanism is a local phenomenon that does not affect other metal cores. On the other side, the dissociative route strongly depends on the MOF internal stability as well as its interaction with the solvent. It happens via an initial inversion of the metal core recovered in the following steps of the reaction.

In both cases, the solvent plays a crucial role as it affects both the stability of the intermediates and the flexibility of the lattice.
We found that this dependence is twofold. If the bond between the solvent and the replacing metal is exceedingly weak, the approaching cluster would easily detach from the lattice (associative mechanism), and the intermediates with $\mathrm{Ni}$ in a $T_{d}$ configuration would be too unstable (dissociative mechanism). If it is too strong, all the steps involving metal-solvent bond cleavage may become more difficult, and the whole energy profile may be shifted up, thus making the reaction very unlikely. In addition, strongly bonded solvents may remain coordinated to the metal core after transmetalation self-limiting the exchange of more ions. This increased stiffness has a positive side effect as it shields the cores from moisture attack. These predictions are consistent with the experiments.

The theoretical study presented here illustrates how simulations can be merged with the state-of-the-art PSIM methodologies. Theory allows an accurate screening of the most commonly used metals for tuning the incorporation of metals into the lattice. The knowledge acquired may improve the synthetic procedures commonly employed or even suggest new ones for ion metathesis.

Theoretical Details. Calculations were performed by means of the density functional theory (DFT) as implemented in the VASP code, version 5.2. ${ }^{44,45}$ The exchange-correlation functional employed was Perdew-Burke-Ernzerhof (PBE), ${ }^{46}$ which reproduces binding energies with reasonable accuracy. ${ }^{47,48}$ Dispersion contributions were added via the Grimme DFT-D2 correction. ${ }^{49}$ Inner electrons were replaced by allelectron frozen cores project-augmented waves (PAW), ${ }^{50,51}$ whereas valence electrons were expanded in plane waves with a cutoff energy of $415 \mathrm{eV}$. Geometries were optimized on a $2 \times 2$ $\times 2 \Gamma$-centered grid until the force threshold of $0.015 \mathrm{eV} / \AA$ was reached. ${ }^{52}$ The setup is similar to that of our previous study. ${ }^{53}$ Convergence tests are presented in section 1 of the Supporting Information. Transition states were located via a scan procedure fixing the positions of the relevant atoms and letting the others free to relax or with the climbing image nudged elastic band method (CI-NEB). ${ }^{54}$ Spin-polarized calculations were run when needed, and different spin states were analyzed in detail for the systems containing two $\mathrm{Ni}$ atoms.

\section{EXPERIMENTAL SECTION}

Materials. $\mathrm{Co}\left(\mathrm{NO}_{3}\right)_{2} \cdot x \mathrm{H}_{2} \mathrm{O}$ (99.9\%, Strem), terephthalic acid (Sigma-Aldrich), and $\mathrm{Zn}\left(\mathrm{NO}_{3}\right)_{2} \cdot \times \mathrm{H}_{2} \mathrm{O}$ (99\%, Alfa) were used as received. Dry, deaerated acetonitrile ( $\mathrm{MeCN}, \mathrm{HPLC}$ grade, Sigma), dichloromethane (DCM, HPLC grade, Honeywell), N,N-dimethylformamide (DMF, 99.8\%, VWR), dimethyl sulfoxide (DMSO, ACS grade, EMD), and tetrahydrofuran (THF, ACS grade, $\mathrm{BDH}$ ) were obtained by degassing with a flow of argon gas for $30 \mathrm{~min}$ and by passing the solvent through two silica columns in a Glass Contour Solvent System. Dimethylacetamide (DMA, 99.9\%, Sigma) was dried over molecular sieves for 2 days, distilled, and degassed under vacuum while frozen. MOF- $5^{55}$ was prepared according to a literature procedure. All the other complexes were reported elsewhere. ${ }^{14}$

Synthetic Aspects of $\mathrm{Co}^{2+}$ Exchange in MOF-5. $\mathrm{Co}\left(\mathrm{NO}_{3}\right)_{2}$. $x \mathrm{H}_{2} \mathrm{O}(0.166 \mathrm{~g})$ was dissolved in $20 \mathrm{~mL}$ of the solvent [DMF, DMSO, THF, or MeCN (see Figure 7)] and added to $\mathrm{Zn}_{4} \mathrm{O}_{13} \mathrm{C}_{24} \mathrm{H}_{12}$ (MOF5) $\left(30 \mathrm{mg}, 4.0 \times 10^{-5} \mathrm{mmol}\right)$ at room temperature and left for 1 week. Afterward, the crystals were collected by gravity filtration and soaked in fresh solvent. The solvent was replaced until UV-vis spectra of the mother liquor no longer displayed absorptions characteristic of $\mathrm{Ni}^{2+}$. 


\section{ASSOCIATED CONTENT}

\section{S Supporting Information}

Convergence tests: k-point sampling, cutoff energies. DMF adsorption energies for the crystallographic and model cells. Basic DMF configurations. DMF adsorption energies in MOF5. Associative mechanism: intermediates and structural parameters for TS $\left(\mathrm{Zn}_{4}^{2} \mathrm{Ni}_{2}^{4} \rightarrow \mathrm{Zn}_{3}^{3} \mathrm{Ni}_{2}^{4}\right)$. Dissociative mechanism: intermediates for the second transmetalation and structural parameters for TS $\left(\mathrm{Zn}_{2}^{4} \mathrm{Ni}_{2}^{4} \rightarrow \mathrm{Zn}_{3}^{1} \mathrm{Ni}_{3}^{3}\right)$. Kinetic derivation for the transmetalation mechanisms: associative and dissociative. Calculation of the interaction energies, $E_{\mathrm{M}-\mathrm{L}}$, for different metals and ligands.

\section{AUTHOR INFORMATION}

\section{Corresponding Author}

*Institute of Chemical Research of Catalonia, ICIQ Av. Pä̈sos Catalans 16, 43007 Tarragona, Spain. Fax: +34 977920231. Telephone: +34 977920229, ext. 307. E-mail: lbellarosa@iciq. es.

\section{Author Contributions}

All the calculations were performed L.B. and M.G.-M. The experimental part was covered by C.K.B. and M.D.

\section{Notes}

The authors declare no competing financial interest.

\section{ACKNOWLEDGMENTS}

Computational studies were supported by the ERC-Starting Grant "Bio2chem-d: Biomass to chemicals: Catalysis design from first-principles for a sustainable chemical industry" (ref ERC-2010-StG-258406) and the generous computational resources provided by BSC-RES. Experimental work (MIT) was supported by the U.S. Department of Energy, Office of Science, Office of Basic Energy Sciences, under Award DESC0006937. The MIT-ICIQ collaboration (travel funds) was made possible through a Global Seed Grant from the MIT International Science and Technology Initiatives center.

\section{REFERENCES}

(1) Li, H.; Eddaoudi, M.; O’Keeffe, M.; Yaghi, O. M. Nature 1999, 402, 276-279.

(2) Brozek, C. K.; Dincă, M. Chem. Soc. Rev. 2014, 43, 5456-5467. (3) Block, W. M.; Burgun, A.; Coghlan, C. J.; Lee, R.; Coote, M. L.; Doonan, C. J.; Sumby, C. J. Nat. Chem. 2014, 6, 906-912.

(4) Wang, Z.; Cohen, S. M. Chem. Soc. Rev. 2009, 38, 1315-1329.

(5) Quartapelle Procopio, E.; Linares, F.; Montoro, C.; Colombo, V.; Maspero, A.; Barea, E.; Navarro, J. A. R. Angew. Chem., Int. Ed. 2010, 49, 7308-7311.

(6) Mondloch, J. E.; Katz, M. J.; Isley, W. C., III; Ghosh, P.; Liao, P.; Bury, W.; Wagner, G. W.; Hall, M. G.; DeCoste, J. B.; Peterson, G. W.; Snurr, R. Q.; Cramer, C. J.; Hupp, J. T.; Farha, O. K. Nat. Mater. 2015, DOI: $10.1038 /$ nmat 4238

(7) Bae, Y.-S.; Hauser, B. G.; Farha, O. K.; Hupp, J. T.; Snurr, R. Q. Microporous Mesoporous Mater. 2011, 141, 231-235.

(8) An, J.; Rosi, N. L. J. Am. Chem. Soc. 2010, 132, 5578-5579.

(9) Lee, Y.; Kim, S.; Kang, J. K.; Cohen, S. M. Chem. Commun. 2015, 51, 5735-5738.

(10) Peplow, M. Nature 2015, 520, 148-150.

(11) Robinson, S. A. K.; Mempin, M.-V. L.; Cairns, A. J.; Holman, K. T. J. Am. Chem. Soc. 2011, 133, 1634-1637.

(12) Wang, Z.; Cohen, S. M. J. Am. Chem. Soc. 2007, 129, 1236812369.

(13) Mukherjee, G.; Biradha, K. Chem. Commun. 2012, 48, 42934295.
(14) Brozek, C. K.; Dincă, M. J. Am. Chem. Soc. 2013, 135, 1288612891.

(15) Zhang, Z.; Zhang, L.; Wojtas, L.; Nugent, P.; Eddaoudi, M.; Zaworotko, M. J. J. Am. Chem. Soc. 2012, 134, 924-927.

(16) Prasad, T. K.; Hong, D. H.; Suh, M. P. Chem.-Eur. J. 2010, 16, 14043-14050.

(17) Wang, X.-L.; Li, P.-Z.; Liu, L.; Zhang, Q.; Borah, P.; Wong, J. D.; Chan, X. X.; Rakesh, G.; Li, Y.; Zhao, Y. Chem. Commun. 2012, 2012, 10286-10288.

(18) Yao, Q.; Sun, J.; Li, K.; Su, J.; Peskov, M. V.; Zou, X. Dalton Trans. 2012, 41, 3953-3955.

(19) Huang, S.; Li, X.; Shi, X.; Hou, H.; Fan, Y. J. Mater. Chem. 2010, 20, 5695-5699.

(20) Mi, L.; Hou, H.; Song, Z.; Han, H.; Fan, Y. Chem.-Eur. J. 2008, $14,1814-1821$

(21) Denysenko, D.; Werner, T.; Grzywa, M.; Puls, A.; Hagen, V.; Eickerling, G.; Jelic, J.; Reuter, K.; Volkmer, D. Chem. Commun. 2012, 48, 1236-1238.

(22) Li, J.; Li, L.; Hou, H.; Fan, Y. Cryst. Growth Des. 2009, 9, 45044513.

(23) Botas, J. A.; Calleja, G.; Sánchez-Sánchez, M.; Orcajo, M. G. Langmuir 2010, 26, 5300-5303.

(24) Brozek, C. K.; Dincă, M. Chem. Sci. 2012, 3, 2110-2113.

(25) Lalonde, M. B.; Bury, W.; Karagiaridi, O.; Brown, Z.; Hupp, J. T.; Farha, O. K. J. Mater. Chem. A 2013, 1, 5453-5468.

(26) Brozek, C. K.; Bellarosa, L.; Soejima, T.; Clark, T. V.; López, N.; Dincă, M. Chem.-Eur. J. 2014, 6871-6874.

(27) Takaishi, S.; DeMarco, E. J.; Pellin, M. J.; Farha, O. K.; Hupp, J. T. Chem. Sci. 2013, 4, 1509-1513.

(28) Bury, W.; Fairen-Jimenez, D.; Lalonde, M. B.; Snurr, R. Q.; Farha, O. K.; Hupp, J. T. Chem. Mater. 2013, 25, 739-744.

(29) Karagiaridi, O.; Bury, W.; Sarjeant, A. A.; Stern, C. L.; Farha, O. K.; Hupp, J. T. Chem. Sci. 2012, 3, 3256-3260.

(30) Karagiaridi, O.; Lalonde, M. B.; Bury, W.; Sarjeant, A. A.; Farha, O. K.; Hupp, J. T. J. Am. Chem. Soc. 2012, 134, 18790-18796.

(31) Burnett, B. J.; Barron, P. M.; Hu, C.; Choe, W. J. Am. Chem. Soc. 2011, 133, 9984-9987.

(32) Yang, G.-S.; Lang, Z.-L.; Zang, H.-Y.; Lan, Y.-Q.; He, W.-W.; Zhao, X.-L.; Yan, L.-K.; Wang, X.-L.; Su, Z.-M. Chem. Commun. 2013, 49, $1088-1090$

(33) Majano, G.; Martin, O.; Hammes, M.; Smeets, S.; Baerlocher, C.; Pérez-Ramírez, J. Adv. Funct. Mater. 2014, 24, 3855-3865.

(34) Valtchev, V.; Majano, G.; Mintova, S.; Perez-Ramirez, J. Chem. Soc. Rev. 2013, 42, 263-290.

(35) Dzubak, A. L.; Lin, L.-C.; Kim, J.; Swisher, J. A.; Poloni, R.; Maximoff, S. N.; Smit, B.; Gagliardi, L. Nat. Chem. 2012, 4, 810-816.

(36) Lin, L.-C.; Lee, K.; Gagliardi, L.; Neaton, J. B.; Smit, B. J. Chem. Theory Comput. 2014, 10, 1477-1488.

(37) Wilmer, C. E.; Leaf, M.; Lee, C. Y.; Farha, O. K.; Hauser, B. G.; Hupp, J. T.; Snurr, R. Q. Nat. Chem. 2012, 4, 83-89.

(38) Crabtree, R. H. The Organometallic Chemistry of the Transition Metals, 4th ed.; John Wiley and Sons Inc.: Hoboken, NJ, 2005.

(39) Bellarosa, L.; Castillo-Sánchez, J. M.; Vlugt, T. J. H.; Calero, S.; López, N. Chem.-Eur. J. 2012, 18, 12260-12266.

(40) This decoordination is unavoidable even when the structure is preoptimized fixing the $\mathrm{Zn}_{\beta}-\mathrm{O}_{\mathrm{c}}$ distance and placing $\mathrm{Zn}_{\mathrm{a}}$ large distances from $\mathrm{O}_{c}$. When all these structures are left to relax without constraints, the $\mathrm{Zn}_{\beta}-\mathrm{O}_{c}$ bond always breaks unavoidably and $\mathrm{Zn}_{\mathrm{a}}$ coordinates back to $\mathrm{O}_{c}$.

(41) Smrčina, M.; Vyskočil, Š.; Hanuš, V.; Polášek, M.; Langer, V.; Chew, B. G. M.; Zax, D. B.; Verrier, H.; Harper, K.; Claxton, T. A.; Kočovský, P. J. Am. Chem. Soc. 1996, 118, 487-488.

(42) Sabatier, P. Ber. Deutch. Chem. Ges. 1911, 44, 1984-2001.

(43) Nørskov, J. K.; Studt, F.; Abild-Pedersen, F.; Bligaard, T. Fundamental Concepts in Heterogeneous Catalysis; Wiley: New York, 2014.

(44) Kresse, G.; Hafner, J. Phys. Rev. B 1993, 47, 558-561.

(45) Kresse, G.; Furthmuller, J. Phys. Rev. B 1996, 54, 11169-11186. 
(46) Perdew, J. P.; Burke, K.; Ernzerhof, M. Phys. Rev. Lett. 1996, 77, 3865-3868.

(47) Zhang, Y.; Pan, W.; Yang, W. J. Chem. Phys. 1997, 107, 79217925.

(48) Patton, D. C.; Pederson, M. R. Phys. Rev. A 1997, 56, R2495R2498.

(49) Grimme, S. J. Comput. Chem. 2006, 27, 1787-1799.

(50) Blöchl, P. E. Phys. Rev. B 1994, 50, 17953-17979.

(51) Kresse, G.; Joubert, D. Phys. Rev. B 1999, 59, 1758-1775.

(52) Mueller, T.; Ceder, G. J. Phys. Chem. B 2005, 109, 1797417983.

(53) Bellarosa, L.; Gutiérrez-Sevillano, J. J.; Calero, S.; López, N. Phys. Chem. Chem. Phys. 2013, 15, 17696-17704.

(54) Henkelman, G.; Uberuaga, B. P.; Jónsson, H. J. Chem. Phys. 2000, 113, 9901-9904.

(55) Kaye, S. S.; Dailly, A.; Yaghi, O. M.; Long, J. R. J. Am. Chem. Soc. 2007, 129, 14176-14177. 